\title{
ENERGY LANDSCAPES Modeling of Renewable Energy Resources with an Emphasis on Northern Germany
}

\author{
P. Michael link, Jürgen Böhner, Hermann Held, and Jürgen Scheffran
}

$R$ enewable energy production plays an important role in northern Germany. In addition to substantial energy production from wind turbines, electricity generation from biomass has become a vital source of income in rural areas of Germany's northern federal states. The use of renewables is still expanding, with a variety of associated challenges for land use. Is renewable energy production a blessing or a curse? How does the infrastructure for energy production and transport to the areas with high demand have to be upgraded to allow for a further increase of the share of renewables in Germany? Can spatial

AFFILIATIONS: LINK-Research Group Climate Change and Security, Center for Earth System Research and Sustainability, and Faculty of Mathematics, Informatics and Natural Sciences, Institute of Geography, and Research Unit Sustainability and Global Change, Center for Earth System Research and Sustainability, University of Hamburg, Hamburg, Germany; BÖHNER-Faculty of Mathematics, Informatics and Natural Sciences, Institute of Geography, University of Hamburg, Hamburg, Germany; HeLD- Research Unit Sustainability and Global Change, Center for Earth System Research and Sustainability, University of Hamburg, Hamburg, Germany; SCheffran-Research Group Climate Change and Security, Center for Earth System Research and Sustainability, and Faculty of Mathematics, Informatics and Natural Sciences, Institute of Geography, University of Hamburg, Hamburg, Germany CORRESPONDING AUTHOR: P. Michael Link, michael.link@uni-hamburg.de

DOI:10.1175/BAMS-D-17-0295.I

In final form 16 November 2017

(C)2018 American Meteorological Society

For information regarding reuse of this content and general copyright information, consult the AMS Copyright Policy.

\section{MODELLERUNG ERNEUERBARER ENERGIERESSOURCEN (MODELING OF RENEWABLE ENERGY RESOURCES)}

WHAT: A group of scientists discussed issues of the modeling of renewable energy resources within the context of climate change and land use with an emphasis on northern Germany, providing current research results, identifying knowledge gaps, and discussing emerging research questions.

WHEN: 17 July 2017

WHERE: Hamburg, Germany planning of the renewable energy sector be improved using simulation models? These are some issues that were addressed during this second conference focused on energy landscapes in northern Germany, ${ }^{1}$ which took place at the University of Hamburg on 17 July 2017. This conference was a follow-up to an earlier conference on energy revolution and space that took place in 2016. While the initial event mainly looked at the energy transition in Germany, with a particular emphasis on land-use issues and challenges with

\footnotetext{
${ }^{1}$ The conference was co-organized and funded by the Center for Earth System Research and Sustainability (CEN) at the University of Hamburg together with the Cluster Renewable Energies in Hamburg (EEHH), involving researchers of the Institute of Geography, the Research Unit Sustainability and Global Change (FNU), and the Research Group Climate Change and Security (CLISEC) of the Excellence Cluster for Integrated Climate System Analysis and Prediction (CliSAP). The conference program is available at www .cen.uni-hamburg.de/research/sustainable-strategies /energylandscapes/conference-energy2017/program.html.
} 
regard to the spatial requirements of energy production in Germany, the second conference focused especially on the aspects of spatial modeling of renewable resources. Modeling has become a fundamental tool in the planning process of the energy transition to identify and remediate possible local land-use conflicts associated with renewables as they require substantially more space than fossil resources.

Almost 160 participants from various scientific disciplines, such as meteorology and other natural sciences, geography, sociology, engineering, and economics, as well as participants from governmental and nongovernmental organizations, met to address these questions. Nine presentations and a concluding panel allowed for in-depth discussions of the socioeconomic aspects of renewable energies, of methods and models of renewable energy production, and of the boundary conditions that are necessary for a successful further development of renewable energy production.

\section{SOCIOECONOMIC ASPECTS OF RENEWABLE ENERGY PRODUCTION.}

Economic assessments indicate that a further increase in global use of renewable energy sources is mandatory in conjunction with other options to protect the climate system cost efficiently and limit average global warming to $2^{\circ} \mathrm{C}$. However, this increases spatial demands for energy production, which may result in conflicts with other land uses. Furthermore, the energy transition poses new challenges with regard to public acceptance, particularly if new technologies are installed in direct proximity to human settlements and traditional land uses. Economic, geographic, and technical assessments using modeling and simulation can be applied, for example, to wind and bioenergy to help reduce potential conflicts with these renewable energy sources and to improve the efficiency of spatial planning processes.

Several presentations highlighted the potential of bioenergy production. While there is substantial theoretical potential for energy generation from biomass, and the production process is already technically quite advanced, the economic potential is comparably limited. Rather than becoming one of the main sources of electricity production, bioenergy can be expected to fill some niches as it is particularly efficient in regions with substantial organic waste from other agricultural activities. Furthermore, there are feedbacks between biomass growth for energy production and food production, water availability, and ecosystems that can trigger local or regional conflicts if neglected. Model simulations indicate that land-use disputes may also arise if large shares of agricultural land are devoted to growing energy crops. Not only does this increase the competition with agricultural food production, but land conversion to expand energy crop production is also likely to have adverse effects on biodiversity in surrounding ecosystems. On the other hand, bioenergy can help to successfully implement the energy transition in small cities in otherwise rural areas. Geographical information system data are a helpful tool in the planning process to identify synergies that can be exploited to optimize the efficiencies of electricity and heat, which are locally produced by renewable energy sources.

\section{METHODS AND MODELS FOR THE ASSESSMENT OF RENEWABLE ENERGY RESOURCES. Energy production from renewable} sources has much more pronounced land-use requirements than energy production from fossil resources. The demand for space is particularly pronounced in wind energy production as wind turbines have become the predominant artificial landmarks in northern Germany and there is substantial regulation of minimum distances, clustering of turbines, etc. To optimally manage this scarce resource "space," it is necessary to support the many different land-use planning processes by providing high quality data on wind potential that are spatially and temporally explicit. Despite the fact that regional climate modeling has improved drastically during the past decade, outdated standards are still applied in the planning process that do not take advantage of the capabilities of current state-of-the-art models and data packages. The second session of the conference focused on such innovative modeling concepts and discussed possibilities of implementing the potential of current regional modeling approaches into land-use planning processes.

Up-to-date climate information is one fundamental requirement to successfully operating decision support systems in the planning process of critical energy infrastructure. These data need to be complemented by numerical models that incorporate current knowledge about regional and local meteorological phenomena. There is a growing demand from the renewable energy industry for simulation results using such models, as this information can have substantial implications for the implementation of large-scale renewable energy projects such as offshore wind parks. These wind parks have considerable effects on atmospheric processes at the local scale, leading to measurable regional impacts. Nonetheless, it is necessary to validate model results by in situ measurements 
because the simulation of meteorological processes in the vicinity of offshore wind parks is a challenge as a result of the dominant effects of turbulence and the small scale of many processes that need to be considered. The same is true for the modeling of solar energy production. In addition to the widely used satellite data, further spectral data and information on spatial variability are often necessary. In comparison to other data sources, data on aerosols in the atmosphere are generally of inferior quality so that it remains necessary to complement simulation model results with high quality pyranometers measuring solar irradiance.

\section{CONDITIONS FOR SUCCESSFULLY DEVELOPING RENEWABLE ENERGIES}

FURTHER. If models of energy production and distribution are to be applied to real energy landscapes, the given local conditions and interactions with regard to ecology, geography, economy, and political boundary conditions need to be adequately considered. This includes life cycle analyses of the infrastructure to transport energy and the associated flows of energy and matter and a look at the economic and social relationships (mobility, labor, social networks). Other important aspects are the political motivations to support the expansion of renewable energy production and the related possibilities for financial support within the context of the overarching energy transition and climate change. One emphasis of the processes of defining specific criteria for all of these quantities should be to minimize potential conflicts between stakeholders and to identify possible win-win solutions.

If such solutions can be implemented, it is possible that the German energy system can be transformed in a way that allows for the population to be supplied with energy from renewable sources by 2050 in a sustainable and ecologically viable way. However, this requires the prompt implementation of technological innovations and an increased flexibility in the decision-making process by stakeholders. This can be achieved not only by monitoring society's overall energy demand but also by setting ambitious political goals for the implementation of the energy transition as a basis for planning. One regional project in northern Germany designed to help achieve this goal is called NEW 4.0 ("Norddeutsche EnergieWende"). It is a consortium of more than 60 partners from industry, science, and politics collaborating to conduct large-scale tests in practice to prove that energy provision and grid reliability can be achieved even if energy production entirely relies on renewable sources. This is being done by designing intelligent production patterns for the different renewable energy sources to optimally distribute the burden of energy production spatially and temporally. In addition to technological progress and innovation, this approach identifies necessary regulatory changes and shows how a successful implementation can have a profound influence on the societal acceptance of renewable energy sources. A similar initiative called WindNODE exists in the Berlin, Germany, area.

\section{SYNTHESIS OF THE INSIGHTS ON ENERGY LANDSCAPES IN NORTHERN GERMANY. One of the key issues of the energy} transition to renewable sources is how a sustainable energy supply influences land use and landscape appearance. Renewable energy sources such as bioenergy or wind energy have substantial spatial requirements. Continued expansion of these means of energy production can lead to conflicts with competing forms of land use. Research at the University of Hamburg not only addresses the technological and economic aspects of energy production from renewables but also incorporates spatial planning and the given political setting to model possible pathways of a successful energy transition. A given area not only needs to be suitable for energy production in terms of its physical characteristics and its location, but energy production also needs to be integrated with other land uses and has to be accepted by local populations. All these aspects were combined at this conference to obtain an overview of the given modeling approaches to renewable energy production and to discuss model results with stakeholders from the sciences, politics, and civil society to reduce potential conflict.

Initially, the energy transition was well accepted by the general public, particularly by environmentalists and activists against nuclear energy. However, some projects intended to expand the share of renewable energy production are now being challenged as well, mainly for changing the landscape appearance. In Germany, nature conservation is highly regarded and conflicts arise between interest groups if, for example, bird populations are affected by the construction of wind turbines. The competition for agricultural land to either grow food crops or energy crops is also a source of potential societal conflict, especially since the given amount of agricultural land in Germany can hardly be expanded further. Therefore, it is necessary to design the uses of renewable energy sources in an environmentally and socioeconomically sound way. A comparison with fossil and nuclear energy sources may serve as a guardrail here as these also alter the 
environment and present considerable risks and potential conflicts. Simulation modeling and assessments using geographical information system data can provide valuable insights for planning purposes as the impacts of different technological, political, and societal development pathways can be assessed, identifying potentially conflictive scenarios.

CONCLUSIONS. The aim of this conference was to present scientific models and scenarios of possible developments of energy landscapes in order to assess potential consequences and the necessary boundary conditions for a successful energy transition in Germany. The presentations highlighted that the underlying assumptions and criteria have a profound impact on model results and that politics and society have the means to fundamentally shape these variables; that is, they have considerable influence on the likelihood of the success of the energy transition. Within the given governance framework, optimal allocations of renewable energy sources can be deduced. This includes the placement of wind turbines in a given landscape setting, the improvement of energy transport infrastructure to make energy produced in rural areas more readily available in urban areas where demand is greater, and matching the supply and demand by application of intelligent energy production patterns. To reduce potential conflicts, the planning processes need to include stakeholders from all involved areas of interest, in much the same way as the discussions during the concluding panel of this conference, which featured energy producers, politicians, scientists, and environmental activists talking about energy conflicts and possible solutions. 